\title{
Composite leading indicators of economic activity: An application to Rio de Janeiro's upstream oil and gas industry
}

\author{
Rafael Gonçalves Patrocínio ${ }^{\dagger}$ \\ Jéfferson Augusto Colombo
}

\begin{abstract}
This paper proposes a monthly composite leading indicator (CLI) to anticipate turning points in the economic activity of Rio de Janeiro's upstream oil and gas industry, from January 2002 to May 2019. First, we build a database with 61 series, and categorize each of them into i) rapidly responsive to economic activities; ii) expectationsensitive; or iii) prime movers indicators. Next, we remove the seasonality of the series through the X-13 ARIMA-SEATS method and use the Bry-Boschan algorithm to identify the cycles. Then, we evaluate the components' fit to integrate the composite leading indicator through four statistical tests: cross-correlation, quadratic probability score, Granger causality, and probit. The assessment of the composite leading indicator demonstrates that it leads $67 \%$ of the peaks and $100 \%$ of the troughs in the target series ( $5 / 6$ of the turning points). The average leading period is 8.4 months, the median is 9 months and the standard error is 2.8 months. Diebold-Mariano tests confirm that adding lags to our CLI improves predictive accuracy. We contribute to the literature by creating, to our knowledge, the first leading indicator for the oil and gas industry in Brazil.
\end{abstract}

Keywords: Business cycles; Rio de Janeiro; Oil and gas; Composite leading indicator; Cross-correlation; Quadratic probability score

JEL Code: E3, C41, C43, C53.

\section{Introduction}

Anticipating upturns and downturns in business cycles is a key competitive advantage for companies and a powerful tool for policymakers. Since Mitchell and Burns (1938 and 1946), economic forecasting has attracted attention. A vast literature covers the measurement and the anticipation of economic activity in global, national, and sectoral levels. However, as Lucas (1977) defines, business cycles are easily misunderstood since they commonly refer to co-movements in different forms of economic activity, not just fluctuations in Gross Domestic Product (GDP).

In this paper, we construct a composite leading indicator (CLI) to the upstream oil and gas economic activity in the state of Rio de Janeiro. The

Submitted on February 8, 2020. Revised on May 25, 2020. Accepted on June 9, 2020. Published online in July 2020. Editor in charge: Marcelo Fernandes.

†Catavento Consultoria de Gestão e Negócios em Sustentabilidade, Brazil: rafael_ patrocinio_6@hotmail.com

${ }^{\ddagger}$ Sao Paulo School of Economics - FGV, Brazil: jefferson. colombo@fgv. br 
starting point for a composite leading indicator is the choice of the target variable. In this sense, we choose IBGE's Pesquisa Industrial Mensal - Produção Física (Monthly industrial survey - physical production) for Rio de Janeiro's extractive industry as the target. The Pesquisa Industrial Mensal - Produção Física (PIM-PF) provides short-term fluctuations for extractive and transformation industries' real products since 1970. Since May 2014, PIM-PF has followed a new methodology; however, there was no break for the series dated back since 2002 .

The upstream oil and gas sector is Rio de Janeiro's primary extractive industry and plays a key role in the state's economy. The sector is responsible for direct jobs, tax revenues, and investments, and provides a strategic raw material for economic and social development. Petroleum production royalties represented 18\% of Rio de Janeiro's state revenue in 2018 (Secretária da Fazenda do Rio de Janeiro, 2019). At the same time, it is also a multiplier for the state's economy, since service industries are intertwined with the upstream oil and gas sector. That said, anticipating changing business cycles in Rio de Janeiro's upstream oil and gas economic activity may contribute positively to a significant number of stakeholders.

The composite leading indicator in this paper follows the OECD's (2012) recommendation. The construction method has five steps: series pre-selection, seasonal adjustment, cycle identification, evaluation, and aggregation. First, we classify the potential leading indicators into three categories: rapidly responsive to economic activities, expectation-sensitive, and prime movers. We benefit from multiple public sources to gather the candidate leading series, such as ANP, BCB, CBOE, CNI, Eletrobras, EIA, FGV, Firjan, IBGE, OECD, Yahoo Finance, and others. Second, we remove seasonal patterns in the series and identify the cyles. Then, we evaluate the series best fit to integrate the composite leading indicator through four statistical tests: (i) cross-correlation (Hollauer, Issler, and Notini, 2009; Oliveira, 2016; NYU, 2017; Issler and Pimentel, 2019); (ii) quadratic probability score (Chauvet, 2000; Issler, Notini, and Rodrigues, 2009); (iii) Granger-causality (Issler, Notini, and Rodrigues, 2009; Oliveira, 2016); and (iv) probit (Morais and Chauvet, 2011). Finally, we use The Conference Board's (2001) aggregation method. Finally, we compare the predictive accuracy of autoregressive (AR) and vector-autoregressive (VAR) models - the latter includes lags of the CLI - using the DieboldMariano Test (Diebold and Mariano, 2002).

Our paper connects to the literature on measuring and analyzing business cycles in Brazil (see, for example, Chauvet, 2000; Picchetti and Toledo, 2002; Issler, Notini, and Rodrigues, 2009; Hollauer, Issler, e Notini, 2009; Morais and Chauvet, 2011; Oliveira, 2016; Campelo Jr., Issler and Pimentel, 
2019; Ozyildirim, Sima-Friedman, Picchetti, and Lima, 2019). Specifically, we contribute to a more scarce literature that measures and analyzes cyclical aspects of specific sectors and industries, which has been done for industrial activity (Hollauer, Issler, and Notini, 2009), the capital goods industry (Chauvet and Morais, 2011), and the construction sector (Cruz and Colombo, 2018). To our knowledge, there is still a gap for the extractive industry. This paper provides the first composite leading indicator to Rio de Janeiro's upstream oil and gas industry economic activity.

The sections in this paper are organized as follows. Section 2 contains a brief review of international and Brazilian literature regarding composite leading indicators. Section 3 describes the methodology. Section 4 analyzes the main results of the paper and reports the assessment of the composite leading indicator constructed. Finally, Section 6 concludes with the main findings and further studies.

\section{Review of literature}

\subsection{Composite leading indicators in the global landscape}

Composite leading indicators research began back in the 1930s when Burns and Mitchell (1938 and 1946) developed a pioneering work concerning business cycles. They developed a list of leading, coincident and lagging series of economic activity in the United States in an effort to explain the recession that began in 1937. As stated by Mitchell and Burns:

"Business Cycles are a type of fluctuation found in the aggregate economic activity of nations that organize their work mainly in business enterprises. A cycle consists of expansions occurring at about the same time in many economic activities, followed by similarly general recessions, contractions, and revivals which merge into the expansion phase of the next cycle; this sequence of changes is recurrent but not periodic; in duration business cycles vary from more than one year to ten or twelve years." (Burns and Mitchell, 1946, p 3)

Early attempts to explain business cycles were not unanimously approved. Koopsmans (1947) considered Mitchell and Burns' work excessively empirical, but the authors disagreed and re-affirmed that the work was fundamentally based on the economic theory.

Moore (1961) added other series to the initial list proposed by Mitchell and Burns in the context of the post-war business transformation. Following 
this idea, Moore and Shiskin (1967) developed composite leading, coincident, and lagging indicators by a combination of the series. Recessions and expansions do not have a single explanation, as economic theory and experience have demonstrated. That said, a combination of series into a composite indicator may better explain signals from different sectors of the economy.

New methods for composite indicators have appeared successively, from heuristical to more complex models. The Conference Board (TCB) has published composite leading, coincident, and lagging indicators of economic activity in the United States since 1995, through a methodology that requires no estimation based on formal econometric models. Alternatively, Stock and Watson (1988a, 1988b, 1989, 1993) propose construction methods using sophisticated econometric and statistical techniques. However, a major failure in Stock and Watson's model was the missing US recession in 1990-1991 (Issler, 2009). Chauvet and Piger (2008) compare the real-time performance of business cycle dating methods and find that both the Bry-Boschan algorithm and a Markov-switching dynamic-factor model have accurately identified the NBER business cycle chronology over the past 30 years. Duarte, Issler and Spacov (2004) compare the state of the economy dating abilities from TCB's method and a series of alternative econometric-based models. Despite the simplicity present in TCB's method, the results are notably satisfactory.

Finally, since the 1970s, OECD has provided a system of composite leading indicators. OECD (2012) details the construction process in four steps: pre-selection, filtering, evaluation, and aggregation. This paper follows those steps, and they will be further described in Section 3. For further reading on leading indicators, we recommend Lahiri and Moore (1992) and Marcellino (2006). For in-depth analyses of business cycles, we suggest Diebold and Rudebusch (1999).

\subsection{Composite leading indicators in Brazil}

Contador (1977) and Contador and Ferraz (1999) developed pioneering work on coincident and leading indicators in Brazil, followed by Chauvet (2001, 2002) and Picchetti and Toledo (2002). In 2002, IBGE redesigned the Pesquisa Mensal do Emprego (Monthly Employment Survey) which characterized a major drawback in composite indicators research, since long-term series are crucial for business cycle analysis. Research and development of composite indicators in Brazil face major challenges regarding the frequency, timeliness, revision, and length of the series. Data should be available in monthly frequency, shortly after the period to which it refers, with no significant revision and no breaks in the life span. Despite these challenges, Duarte, 
Issler, and Spacov (2004) compare three alternative indicators for Brazilian economic activity and establish a recession chronology. Ellery Junior (2002) analyzes the empirical relationship between GNP and key factors, such as investment, work hours, consumption and productivity. Chauvet and Morais (2008) construct a composite leading indicator to anticipate downturns in the Brazilian business cycle through a time-varying autoregressive probit model.

Other business cycle studies have been developed for Brazil in order to understand sector specificities. Hollauer, Issler and Notini (2009) construct a composite coincident indicator for Brazilian industrial activity through a comparison of The Conference Board's (TCB) method, linear dynamic models and the Mariano-Murasawa approach. They conclude that TCB's method is superior for this purpose. Morais and Portugal (2008) develop a composite coincident indicator of industrial activity in the state of Rio Grande do Sul.

Even though composite coincident indicators have already been exhaustively studied in Brazil, there is still room to advance in composite leading indicators for sectoral analysis. To address this, Campelo Junior (2008) develops a composite leading indicator for Brazilian industrial activity; Morais (2005) studies business cycles of industrial activity in the state of Bahia; Chauvet and Morais (2011) construct a composite leading indicator for the Brazilian capital goods industry through a time-varying autoregressive probit model; and Morais (2013) analyzes cycles and leading indicators of Rio Grande do Sul's industrial activity. As far as we know, a composite leading indicator to the petroleum extractive industry of the state of Rio de Janeiro has not previously been constructed.

\section{Methodology}

In this paper, the business cycle is defined by the turning points in the level of aggregate economic activity (Harding and Pagan, 2002). In this manner, we identify the cycles through the classical approach. Eliminating trends from economic aggregates is difficult, and inadequate estimations may cause significant mistakes (Zarnowitz and Ozyildirim, 2006). The studies of the National Bureau of Economic Research (NBER) follow the classical cycle approach, analyzing expansions and contractions in the level series without trend adjustments. Harding and Pagan (2002) explain that classical business cycle studies do not require a de-trending operation. Additionally, Hamilton (2018) provides evidence that the HP Filter, a widely-used tool for detrending, produces series with spurious dynamic relations. The resulting series have no basis in the true data-generating process. Phillips (2015) also states that the HP Filter fails to eliminate stochastic trends when used as a decomposition device to estimate growth cycles. 
Following OECD (2012), constructing the composite leading indicator to upstream oil and gas economic activity in the state of Rio de Janeiro follows five steps: pre-selection, seasonal adjustment, cycle identification, evaluation, and aggregation.

\subsection{Pre-selection}

First, pre-selection considers the best practices for the choice of reference and component series. The reference series in this article is the PIM-PF for Rio de Janeiro's extractive industry, which is a proxy for business cycles in the upstream oil and gas economic activity in the state. The series is available monthly without breaks since 2002 . We select over 60 indicators as potential components, according to their economic relevance and practical considerations. Table A1, in the appendix, describes each potential leading series, including any adjustment used. We classify all potential component indicators as rapidly responsive to economic activities, expectation-sensitive, or as prime movers. Additionally, we assess them according to frequency, length, timeliness, and revision. The series should have monthly frequency and long life span. Besides, it should also be available as fast as possible with no significant revision in past data.

\subsection{Seasonal adjustment}

The second step considers the seasonal adjustment method. The series are seasonally-adjusted when necessary, followed by outlier detection to avoid discrepancies in the analysis. We use the X-13 ARIMA-SEATS method provided by the US Census Bureau to adjust seasonal patterns and detect outliers. If the series was seasonally adjusted by the source provider, no modification is made in this sense. The target variable, PIM-PF for Rio de Janeiro's extractive industry, is seasonally-adjusted through X-13 ARIMA-SEATS in this paper. Then, the observations of each series $(Y(t))$ are transformed by its natural logarithm form, except for those that may be expressed by negative numbers (i.e. monthly inflation).

\subsection{Cycle identification}

The cycles in this paper are identified through turning points detection without any de-trending. We use the algorithm developed by Bry and Boschan (1971) to identify business cycles turning points in each time series. First, the algorithm detects peaks and troughs in the series as follows (NCER, 2019).

- A peak occurs at time $t$ if

$$
y_{t-k}, \cdots, y_{t-k+1}<y_{t}>y_{t+1}, \cdots, y_{t+k} .
$$


- Similarly, a trough happens at time $t$ when

$$
y_{t-k}, \cdots, y_{t-k+1}>y_{t}<y_{t+1}, \cdots, y_{t+k} .
$$

The variable $k$ is known as the turn phase parameter or symmetric window, and is defined as 5. After the identification of each peak and trough, the series are divided into expansion and contraction phases. However, other restrictions are also introduced to establish a minimum phase and a minimum cycle (expansion + contraction). The minimum phase is set as 5 and the minimum cycle is specified as 15 . In this way, we transform series into binary variables, denoting expansions as 1 and contractions as 0 .

The last procedure in the seasonal adjustment step is normalization, which aims to equalize the series regarding the scale and units. Normalization is carried out by subtracting the mean of the series from each filtered data, dividing the result by the absolute mean deviation and, finally, by adding 100 to each observation (OECD, 2012).

$$
s_{t}=\frac{\left(y_{t}-\mu\right)}{\bar{\sigma}}+100
$$

\subsection{Evaluation}

We evaluate the potential leading series through four statistical tests: crosscorrelation, quadratic probability score, Granger causality, and probit. Following the four tests, a selection criterion defines a set of components that are fit to the composite leading indicator.

\subsubsection{Cross-correlation}

Cross-correlation function (CCF) expresses a measure of the correlation between two time series, ranging in value from -1 to 1 . CCF between $R_{t}$ (target variable) and $s_{t}$ (potential leading series) is defined by the ratio of covariance to root-mean variance (Boyd, 2001).

$$
\mathrm{CCF}=\frac{\sum_{t=1}^{K}\left(R_{t}-\bar{R}\right)\left(s_{t}-\bar{s}\right)}{\sqrt{\sum_{t=1}^{K}\left(R_{t}-\bar{R}\right)^{2} \Sigma_{t=1}^{K}\left(s_{t}-\bar{s}\right)^{2}}}
$$

The cross-correlation widens the concept of correlation to the timing of two series, $\mathrm{CCF}=\operatorname{corr}\left(R_{t}, n_{t+k}\right)$. If $k$ assumes a negative value, the correlation between the two time series is analyzed in the past, while a positive value for $k$ refers to the correlation in the future. We analyze the CCF between the target variable and each potential leading series graphically for $\mathrm{k}$ 
ranging from -24 to 24 . Thus, we can observe the leading and lagging characteristics of the series. Countercyclical series, such as the benchmark interest rate, are inverted $\left(y_{t}^{*}=-y_{t}\right)$.

\subsubsection{Quadratic Probability Score}

The second test applied to evaluate the potential leading series is the Quadratic Probability Score (QPS), originally proposed by Diebold and Rudebusch (1989). This test has also been used by Zhang and Zhuang (2002), Gallardo and Pedersen (2007), Campelo Junior and Issler (2008), Issler, Notini and Rodrigues (2009) and Chauvet and Morais (2011). The objective of the test is to score the candidate leading series according to its capacity to anticipate the state of the economy (expansion or recession) of the reference series. The score is calculated by

$$
\mathrm{QPS}=\frac{\sum_{t=1}^{N}\left(R_{t}-s_{t-k}\right)^{2}}{N} .
$$

We state the reference series $\left(R_{t}\right)$ and the candidate leading series $\left(s_{t}\right)$ as binary variables according to the Bry Boschan algorithm results, where 1 is given to expansion phases and 0 refers to recessions. Therefore, the QPS results range from 0 to 1 by construction, with 0 indicating a perfect fit between the series. We apply the test for lags $(k)$ ranging from 1 to 16 and identify the best performers, as well as the optimum lag.

\subsubsection{Granger-causality}

The third test applied in this paper to evaluate potential leading series is Granger-causality. Granger (1969) examines whether forecasts of future values of a reference series may be better explained if the present and lagged values of another series are also considered. In this sense, Granger proposes the following definitions for causality between two series denoted as $X$ and $Y$ :

(i) Granger-causality. $X$ Granger-causes $Y$ if past values of $X$ help predict $Y$, given the information contained in the lagged values of $Y$.

(ii) Feedback. Feedback happens if $X$ Granger-causes $Y$ and $Y$ Grangercauses $X$.

We apply the Granger-causality test to the series in level and in the stationary form. Therefore, prior to the causality test, we verify the stationarity of each series through the Augmented Dickey-Fuller (ADF) test and adjust 
when necessary. Next, we use the Akaike Information Criteria (AIC) test to identify the optimum lag between the reference and leading candidate series. Then, we verify the Granger-causality in the optimum lag. The series is only accepted if the Granger-causality test points to a performance in the direction expected for a leading indicator (Definition (i)). Definitions (ii) and (iii), feedback and instantaneous causality, respectively, are not accepted, following Campelo Junior and Issler (2008) and Issler, Notini and Rodrigues (2009).

\subsubsection{Probit}

The last test is the probit approach. This model is adopted by Estrella and Mishkin (1998) to evaluate the leading characteristics of series. It aims to compute probabilities that a contraction $\left(Y_{t}\right)$ will occur at given values of a leading indicator candidate $\left(s_{t}\right)$. The variable $Y_{t}$ is defined as follows:

$$
Y_{t}=\left\{\begin{array}{ll}
1, & \text { recession phase } \\
0, & \text { otherwise }
\end{array} .\right.
$$

The probability of obtaining $Y_{t}=1$ is linked to a latent variable, $I$. In this article, the variable $I$ represents the business cyle phases. In the probit model it may be defined as $I=\beta_{0}+\beta s_{t-k}$.

$\beta_{0}$ and $\beta$ are the regression coefficients, while $k$ is the leading period. Next, it is necessary to set a threshold value, $I^{*}$, to indicate the occurrence of a recession phase. If the unobservable variable $I$ is greater than $I^{*}$, it means $Y_{t}=1$. Therefore, the probit model can be characterized as

$$
\operatorname{Pr}\left(Y_{t}=1 \mid s_{t-k}\right)=\operatorname{Pr}\left(I^{*} \leq I\right)=\phi\left(\beta_{0}+\beta s_{t-k}\right) .
$$

The recession prediction is obtained from the conditional probability of a contraction occurrence, with $k$ months ahead, given a cumulative normal distribution represented by $\phi(\cdot)$.

\subsubsection{Selection criteria}

There is no unique and obvious way to reach an optimum set of leading indicators. Therefore, after the four tests above are applied, we establish the following selection criteria to identify a set of leading indicators that are fit to integrate the composite leading indicator to the economic activity of the extractive industry of the state of Rio de Janeiro.

(i) Absolute maximum correlation between 0 and -12 months in the CCF test. 
Table 1

Selected series for the composite leading indicator

\begin{tabular}{llr}
\hline code & series & classification \\
\hline prod_rj & crude oil production - Rio de Janeiro & rapid responsive \\
exp_pet & crude oil exports - Brazil & rapid responsive \\
elet_cons_SE & electricity consumption in Brazilian southeastern region & rapid responsive \\
petr4 & Petrobras preferential stocks & expectation sensitive \\
Fdi & foreign direct investment & expectation sensitive \\
di_pre_360 & swap DI x pre 360 (inverted) & prime mover \\
\hline
\end{tabular}

(ii) QPS lower than 0.4, following one of the thresholds established by Issler, Notini and Rodrigues (2009).

(iii) Candidate indicators that Granger-cause the reference series and not vice-versa, at the $10 \%$ significance level, using the lag structure suggested by the Akaike information criterion (AIC).

(iv) $p$-value lower than $10 \%$ in the bivariate probit model for the optimum lag defined by the QPS.

(v) Retain only series that satisfy (i), (ii), (iii) and (iv).

Starting with a database of 61 candidate series for leading, and following the above criteria, we end up with six different leading series: crude oil production in Rio de Janeiro, crude oil exports in Brazil, electricity consumption in Brazil's southeastern region, Petrobras preferential stocks, foreign direct investment, and swap DI x Pre 360 days. Table 1 presents the components of the composite leading indicator according to the established method.

The first test, cross-correlation, approves 32 series out of the 61 that composed the initial list. The quadratic probability score accepts 9 out of the 32 remaining series. Next, Granger-causality approves 6 series. And finally, probit validates the 6 remaining series. The individual results of the selected series for each statistical test are presented in the appendix as follows. Figures $\mathrm{A} 1, \mathrm{~A} 2$, and $\mathrm{A} 3$ report the cross-correlation results. Tables $\mathrm{A} 2$ and $\mathrm{A} 3$ demonstrate the results from the quadratic probability score. Tables A4 and A5 show the Granger-causality results. Finally, Table 6 presents the probit results, and Table A7 shows the descriptive statistics of the selected series for the composite leading indicator.

\subsection{Aggregation}

The last step of the composite leading indicator construction is to aggregate the selected series. We use the aggregation method proposed by The 
Conference Board (2001) in this paper. The procedure has four stages, as follows (p. 47).

(i) The month-to-month variation, $r_{i, t}$, is calculated through a symmetric percent change formula for each series.

$$
r_{i, t}=200 \frac{\left(x_{i, t}-x_{i, t-1}\right)}{\left(x_{i, t}+x_{i, t-1}\right)}
$$

(ii) The month-to-month variations are adjusted by the components' standardization factor, $w_{i, t}$. The standard deviation, $\mu_{i}$, of each component is calculated, followed by the sum of the inverse of each one.

$$
k=\sum_{i} \frac{1}{\mu_{i}}
$$

These factors aim to give each component an equal opportunity to contribute to the composite indicator.

$$
c_{i, t}=w_{i} r_{i, t}=\frac{r_{i, t}}{k \cdot \mu_{i}}
$$

(iii) The sum of each month-to-month variation adjusted through the standardization factor is calculated.

$$
s_{t}=\sum_{i} c_{i, t}
$$

(iv) Finally, the composite indicator is computed through the symmetric percent change formula recursively, starting from 100 in the first month, $S_{1}=100$.

$$
S_{t}=S_{t-1} \cdot \frac{\left(200+s_{t}\right)}{\left(200-s_{t}\right)}
$$

Following TCB's (2001) recommendations, to account for changes in the standardization factors over time, we update it annually by recalculating the standard deviation of each component.

\section{Results}

In this section, we present the performance of the composite leading indicator, according to the methodology proposed in this article, and analyze the 


\section{Figure 1}

Comparison between the composite leading indicator (CLI) and PIM-PF for Rio de Janeiro's extractive industry, seasonally adjusted

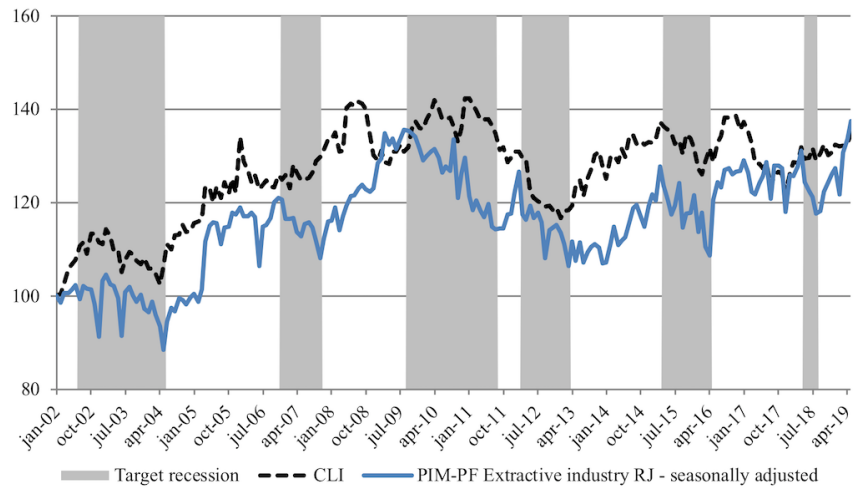

Table 2

Selected series for the composite leading indicator

\begin{tabular}{lcccr}
\hline$\#$ & $\begin{array}{c}\text { turning } \\
\text { point type }\end{array}$ & $\begin{array}{c}\text { target series } \\
\text { turning point's date }\end{array}$ & $\begin{array}{c}\text { CLI turning } \\
\text { point's date }\end{array}$ & $\begin{array}{r}\text { lead (-) } \\
/ \text { lag (+) }\end{array}$ \\
\hline 1 & peak & June 2002 & February 2003 & +8 \\
2 & trough & May 2004 & April 2004 & -1 \\
3 & peak & November 2006 & January 2006 & -10 \\
4 & trough & October 2007 & June 2006 & -16 \\
5 & peak & August 2009 & August 2008 & -12 \\
6 & trough & August 2011 & April 2009 & -28 \\
7 & peak & February 2012 & January 2011 & -13 \\
8 & trough & March 2013 & January 2013 & -2 \\
9 & peak & March 2015 & March 2015 & 0 \\
10 & trough & April 2016 & February 2016 & -2 \\
11 & peak & April 2018 & November 2016 & -17 \\
12 & trough & August 2018 & December 2017 & -8 \\
\hline
\end{tabular}

results. Figure 1 shows the composite leading indicator and the target variable (PIM-PF extractive industry RJ, seasonally adjusted), with its recession phases shaded.

The reference series presents six recessions (shaded areas) and seven expansion phases, totaling twelve turning points in the analyzed period. Table 2 compares the turning points of both series and assesses the leading capacity of the indicator proposed in this article. Both series have twelve turning points from January 2002 to May 2019.

Table 2 shows the composite leading indicator misses two turning points: the recessions beginning in June 2002 and March 2015. Meanwhile, the sixth 
Table 3

Composite leading indicator performance:

Timing measures

\begin{tabular}{lccc}
\hline & \multicolumn{3}{c}{ lead (-)/lag (+) } \\
\cline { 2 - 4 } state of the economy & average & median & standard error \\
\hline recession & -7.3 & -11.0 & 3.8 \\
expansion & -9.5 & -8.0 & 4.3 \\
overall & -8.4 & -9.0 & 2.8 \\
\hline
\end{tabular}

Table 4

Composite leading indicator performance: False signals and leading ratio

\begin{tabular}{lccccr}
\hline state of the economy & leading & coincident & lagging & false signal & leading ratio \\
\hline recession & 4 & 1 & 1 & 0 & $67 \%$ \\
expansion & 6 & 0 & 0 & 0 & $100 \%$ \\
overall & 10 & 1 & 1 & 0 & $83 \%$ \\
\hline
\end{tabular}

turning point, the trough in August 2011, has an excessive leading period (28 months), which is an unsuitable indication. Tables 3 and 4 report the leading performance of the composite indicator for recessions, expansions, and overall phases.

Based on the above results, we observe an asymmetric performance for recessions and expansions. Even though the composite leading indicator demonstrates a satisfactory leading ratio (83\%) for the overall analysis, the capacity to predict downturns is $67 \%$. On the other hand, the composite leading indicator has a perfect score anticipating expansions from January 2002 to May 2019.

Interpreting signals from the leading index is a key aspect of business cycle study. TCB (2001) recommends the Three Ds analysis - duration, depth, and diffusion - to avoid misinterpretation in the short term. According to $\mathrm{TCB}$, reasonable criteria to assess the likelihood of a recession are a $2 \%$ decrease in the index over six months, coupled with downward movements in more than half of the components. Table 5 demonstrates if the recession signals from the composite leading indicator constructed in this article follow the Three Ds criteria suggested by TCB.

Table 5 reports that the recession signals of the composite leading indicator adhere precisely to the Three Ds criteria. Afterward, we compare the composite leading indicator and the target variable adjusted by a three-month moving average. Thus, we verify the performance of the leading indicator followed by a smoothing technique.

Figure 2 demonstrates that the target variable adjusted by a three-month 
Table 5

Three Ds analysis for the composite leading indicator

\begin{tabular}{lcr}
\hline Date - 6 months after peak & Depth - 6 months after peak & Diffusion \\
\hline August 2003 & $-4 \%$ & $67 \%$ \\
July 2006 & $-8 \%$ & $100 \%$ \\
February 2009 & $-7 \%$ & $67 \%$ \\
July 2011 & $-4 \%$ & $67 \%$ \\
September 2015 & $-5 \%$ & $67 \%$ \\
May 2017 & $-7 \%$ & $83 \%$ \\
\hline
\end{tabular}

Figure 2

Comparison between the composite leading indicator (CLI) and PIM-PF for Rio de Janeiro's extractive industry adjusted by a three-month moving average

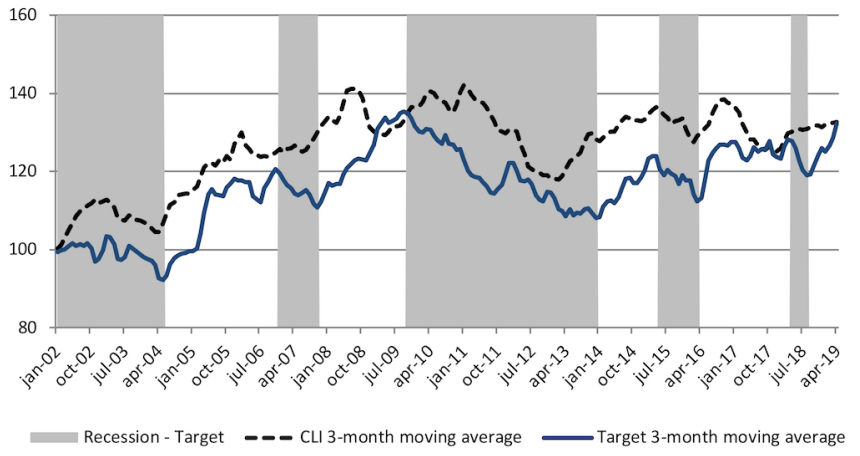

moving average has five recessions and five expansion phases, which results in nine turning points. On the other hand, the adjusted composite leading indicator has seven expansions and six recessions in the period, adding to twelve turning points. The adjusted composite leading indicator misses the beginning of the first recession, has an extra cycle from September 2008 to April 2009, and coincides with the target recession in May 2015. Therefore, we can affirm that the smoothing technique does not improve the assessment of the composite leading indicator proposed.

Finally, a robustness check is done to analyze the performance of the composite leading indicator without Rio de Janeiro's crude oil production component. Even though the indicator was approved with the selection criteria proposed, one may affirm it should be a coincident, instead of a leading indicator. Therefore, we aggregate the other five components into an adjusted composite leading indicator (ACLI) and assess the performance, as reported in Table 6. 
Table 6

Comparison between the adjusted composite leading indicator and the target variable

\begin{tabular}{ccccc}
\hline$\#$ & $\begin{array}{c}\text { turning } \\
\text { point type }\end{array}$ & $\begin{array}{c}\text { target series } \\
\text { turning point date }\end{array}$ & $\begin{array}{c}\text { ACLI turning } \\
\text { point date }\end{array}$ & $\begin{array}{c}\text { lead (-) } \\
\text { /lag (+) }\end{array}$ \\
\hline 1 & peak & June 2002 & September 2002 & +5 \\
2 & trough & May 2004 & April 2004 & -1 \\
3 & peak & November 2006 & January 2006 & -10 \\
4 & trough & October 2007 & October 2006 & -12 \\
5 & peak & August 2009 & June 2008 & -14 \\
6 & trough & Null & April 2009 & false signal \\
7 & peak & Null & January 2011 & false signal \\
8 & trough & August 2011 & November 2011 & +3 \\
9 & peak & February 2012 & April 2012 & +2 \\
10 & trough & March 2013 & January 2013 & -2 \\
11 & peak & March 2015 & June 2015 & +3 \\
12 & trough & April 2016 & February 2016 & -2 \\
13 & peak & April 2018 & November 2016 & -17 \\
14 & trough & August 2018 & December 2017 & -8 \\
\hline
\end{tabular}

Results in Table 6 demonstrate that the adjusted composite leading indicator performs poorly as a tool to anticipate the changing cycles in the target variable. Therefore, we may affirm that crude oil production in Rio de Janeiro contributes positively to the composite leading indicator.

\section{Is the leading indicator useful to forecast the target variable? A ref- erence VAR model to compare predictive accuracy}

Our last empirical step is to analyze the usefulness of the composite leading indicator (CLI) to predict the PIM-PF for Rio de Janeiro's extractive industry (our target variable). In particular, we want to estimate the marginal effect of the lags of the CLI on predicting the current PIM-PF for Rio de Janeiro's extractive industry, after controlling for the lags of the target variable itself. Following Diebold and Rudebusch (1991), we estimate

PIM-PF Extractive Industry in Rio $_{t}=$

$$
=\beta_{0}+\sum_{i=1}^{p} \beta_{i} \cdot \text { PIM-PF Extractive Industry in } \text { Rio }_{t-i-k+1}+\varepsilon_{t}
$$


and

PIM-PF Extractive Industry in Rio $_{t}=$

$$
\begin{array}{r}
=\beta_{0}+\sum_{i=1}^{p} \beta_{i} \cdot \text { PIM-PF Extractive Industry in } \text { Rio }_{t-i-k+1} \\
+\sum_{i=1}^{p} \gamma_{i} \cdot \text { Leading Indicator }{ }_{t-i-k+1}+\varepsilon_{t},
\end{array}
$$

where (12) and (13) stand for the AR(p) and VAR(p) models used to forecast the PIM-PF for Rio de Janeiro's extractive industry. Specifically, PIM-PF Extractive Industry in Rio is the level of the target variable, Leading Indicator is the level of the composite leading index (CLI), $t$ refers to the time period (year-month), $k$ refers to the number of months ahead of the prediction, and $p$ refers to the lag length of the estimated regression. Because we use monthly data, we choose $p=12$.

By estimating (12) and (13), we get two forecasts: $\left\{\widehat{y}_{1 t} ; t=1, \ldots, T\right\}$ (from the AR[12] model) and $\left\{\widehat{y}_{2 t} ; t=1, \ldots, T\right\}$ (from the VAR[12] model). We compare both $\widehat{y}_{1 t}$ and $\widehat{y}_{2 t}$ with the actual values of the PIM-PF for Rio de Janeiro's extractive industry $\left(y_{t}\right)$. Our question is: is the prediction of $y_{t}$ better when we add lags of our composite leading indicator (i.e., are the forecast errors of the VAR model lower than those from the AR model)? Figure 3 shows the forecasts from the AR(12) and VAR(12) models, for both the PIMPF for Rio de Janeiro's extractive industry in levels (Panel A) and change in natural logarithm (i.e., percentage changes, Panel B).

From Figure 3, it seems that the forecast using the VAR(12) model is closer to the actual series of the target variable than the AR(12) model. However, it is nearly impossible to assess predictive performance only graphically. Thus, to compare both predictions with and without the lagged values of the CLI, we define the forecast errors as $e_{\text {it }}=\widehat{y}_{\text {it }}-y_{t}, i=1,2$. The loss associated with each forecast is a function of the forecast error: $g\left(e_{\mathrm{it}}\right)$. Such a loss function $(g[]$.$) is typically the square (squared-error loss) or the absolute$ value (absolute error loss) of $e_{\text {it }}$. We use the Diebold-Mariano test (Diebold and Mariano, 2002) to infer whether the loss differential between the two forecasts $\left(d_{t}=g\left(e_{1 t}\right)-g\left(e_{2 t}\right)\right)$ is statistically different from zero. The "equal accuracy" null hypothesis is equivalent to the test that the population mean of the loss-differential series is 0 (Diebold and Mariano, 2002). Table 7 shows the results from the Diebold-Mariano test of predictive accuracy, using three different loss functions: mean squared errors (MSE), mean absolute errors (MAE), and mean absolute percentage errors (MAPE). 


\section{Figure 3}

PIM-PF for Rio de Janeiro's extractive industry and AR(12) and

\section{$\operatorname{VAR}(12)$ forecasts}

Forecasts with the AR(12) [VAR(12)] model start in Jan. 2003 [Feb. 2003]. VAR(12) model is the AR(12) plus twelve lags of the the composite leading indicator (CLI). In Panel A the target variable - PIM-PF for Rio de Janeiro's extractive industry - is measured in levels and equals 100 in Jan. 2002. In Panel B, the target variable is measured as changes in natural logarithms (i.e., percentage changes), and thus the $y$-axis is interpreted as percentage points (p.p.).
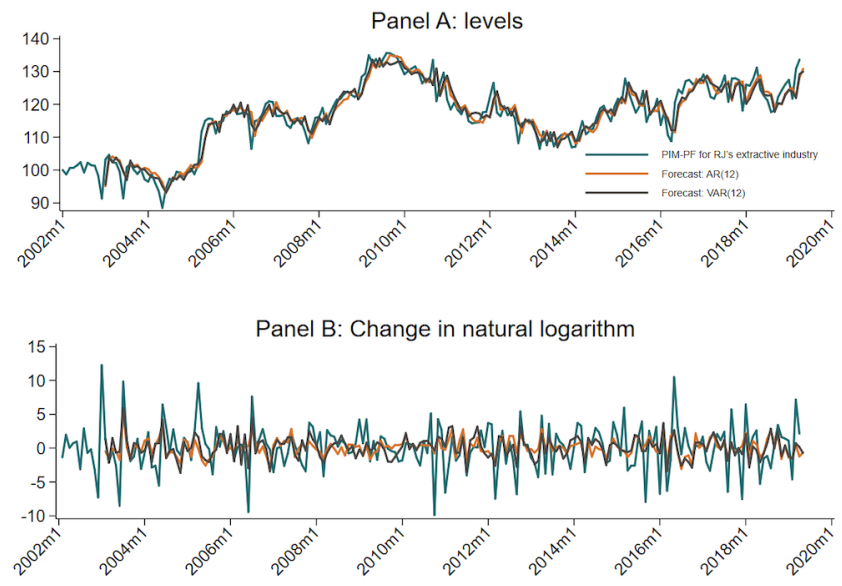

As we can infer from Table 7, the VAR forecasts (i.e., those that include the lags of our CLI) outperform the AR forecasts in the point estimates (i.e., lower errors), regardless of the loss function (MSE, MAE, MAPE). More importantly, these differences in predictive accuracy are statistically meaningful, according to the Diebold-Mariano test (all $p$-values $<0.05$ ). Thus, we conclude that marginally adding lags of our CLI to the model containing lags of the target variable itself (PIM-PF for Rio de Janeiro's extractive industry) improves predictive performance.

\section{Conclusion}

In this paper, we construct a monthly composite indicator to anticipate the business cycles in Rio de Janeiro's extractive industry using OECD's recommendations and TCB's aggregation technique. The proposed indicator leads business cycle turning points by 8.4 months on average, with two failures characterized by one lagging and one coincident recession signal, from January 2002 to May 2019. We observe an asymmetric behavior in the leading 


\section{Table 7}

Diebold-Mariano comparison of predictive accuracy

This table shows the Diebold and Mariano (1995) tests for predictive accuracy. The two competing predictions (AR and VAR) are compared using different loss criteria (MSE, MAE, MAPE). The null hypothesis is that the accuracy of both predictions is the same. MSE stands for mean squared errors; MAE, mean absolute errors; MAPE, mean absolute percentage errors. We implement the test using the "DMARIANO" user-written command for Stata (Baum, 2003). MAPE statistics in Panel B are not calculated because the underlying series is already in percentage changes.

\begin{tabular}{lccc}
\hline \multicolumn{4}{c}{ Panel A: Levels } \\
\hline & MSE & MAE & MAPE \\
\cline { 2 - 4 } forecast (AR) & 12.73 & 2.754 & 0.2371 \\
forecast (VAR) & 11.48 & 2.656 & 0.2279 \\
difference & 1.25 & 0.098 & 0.0092 \\
$p$-value & 0.0074 & 0.047 & 0.0336 \\
better forecast: & forecast(VAR) & forecast(VAR) & forecast(VAR) \\
\hline & Panel B: Change in natural logarithms & \\
\hline & MSE & MAE & MAPE \\
\cline { 2 - 4 } & 9.282 & 2.338 & - \\
forecast (AR) & 8.317 & 2.235 & - \\
forecast (VAR) & 0.965 & 0.103 & - \\
difference & 0.0012 & 0.072 & - \\
$p$-value & forecast(VAR) & forecast(VAR) & - \\
better forecast: & & &
\end{tabular}

indicator since it is able to anticipate all expansions, whereas recessions have a $67 \%$ leading ratio. Regarding the overall performance, the composite leading indicator is able to anticipate $83 \%$ of the turning points. Furthermore, tests comparing the predictive accuracy of AR and VAR models confirm that adding lagged values of our CLI improves the forecast of Rio de Janeiro's extractive industry physical production. To our knowledge, this is the first attempt to create an indicator with this purpose for the oil and gas industry in Brazil.

Composite leading indicators have been studied extensively to enable a timely analysis of business conditions and assist companies, economists, and policymakers to anticipate changing cycles in economic activity. Decisionmakers are continually struggling with the possibility of a sudden downturn shifting the expected direction of the market. Thus, composite indexes may be a powerful tool, since the aggregation of series in one indicator may reveal common turning points from a wide range of data in a more convincing manner than a single component. However, like any other forecasting tool, business-leading indicators should be analyzed cautiously, and enhanced with additional data and information (TCB, 2001).

We suggest that future studies explore more sophisticated econometric 
techniques to refine the series selection criteria proposed in this paper. The upstream oil and gas industry plays a vital role in Rio de Janeiro's economy, through tax revenues, investments, and direct and indirect jobs. Therefore, a leading indicator of the sector may benefit a wide range of stakeholders.

\section{References}

Baum, C. F. (2003). DMARIANO: Stata module to calculate DieboldMariano comparison of forecast accuracy, Statistical Software Components S433001, Boston College Department of Economics, revised 26 Apr 2011.

Boyd, D. W. (2001). Systems Analysis and Modelling, 1st edn, Academic Press.

Bry, G. and Boschan, C. (1971). Cyclical Analysis of Time Series: Selected Procedures and Computer Programs, National Bureau of Economic Research.

Burns, A. F. and Mitchell, W. C. (1938). Statistical Indicators of Cyclical Revivals, National Bureau of Economic Research.

Burns, A. F. and Mitchell, W. C. (1946). Measuring Business Cycles, National Bureau of Economic Research.

Campelo Junior, A. (2008). Indicadores antecedentes de atividade industrial no Brasil, Master's thesis, EPGE/FGV.

Campelo Junior, A. and Issler, J. (2008). Leading indicators of industrial activity in Brazil, Revista Conjuntura Econômica 51.

Campelo Junior, A., Ozyildrim, A., Sima-Friedman, J., Picchetti, P. and Lima, S. P. M. (2019). Coincident and leading indicators for Brazilian cycles, Business Cycles in BRICS, Springer International Publishing.

Chauvet, M. (2000). Leading indicators of inflation for Brazil, Working Paper Series 7, Banco Central do Brasil, Research Department.

URL: https : / /www.bcb.gov.br/pec/wps/ingl/wps 07 .pdf

Chauvet, M. (2001). A Monthly Indicator of Brazilian PIB, Brazilian Review of Econometrics 21: 1-48.

Chauvet, M. (2002). The Brazilian Business Cycle and Growth Cycles, Revista Brasileira de Economia 56: 75-106. 
Chauvet, M. and Morais, I. A. C. (2008). Predicting Recessions in Brazil, LAMES/LACEA Meeting, Rio de Janeiro, Brasil.

Chauvet, M. and Morais, I. A. C. (2011). Leading indicators for the capital goods industry, Brazilian Review of Econometrics 31(1): 137-171.

Chauvet, M. and Piger, J. (2008). A comparison of the real-time performance of business cycle dating methods, Journal of Business and Economic Statistics 26(1): 42-49.

Contador, C. and Ferraz, C. (1999). Previsão com Indicadores Antecedentes, Silcon, Rio de Janeiro.

Contador, R. C. (1977). Ciclos Econômicos e Indicadores de Atividade, Vol. 237, INPES/IPEA.

Cruz, F. I. L. and Colombo, J. A. (2018). Ciclos de negócios na construção civil: Elaboração e análise de indicadores compostos da atividade econômica nacional e regional do setor, Ensaios FEE 38(4): 733-772.

Diebold, F. and Mariano, R. (1995). Comparing predictive accuracy, Journal of Business and Economic Statistics 13(3): 253-263.

Diebold, F. X. and Rudebusch, G. D. (1989). Scoring the leading indicators, Journal of Business 62(3): 596-616.

Diebold, F. X. and Rudebusch, G. D. (1991). Forecasting output with the composite leading index: A real-time analysis, Journal of the American Statistical Association 86(415): 603-610.

Diebold, F. X. and Rudebusch, G. D. (1999). Business Cycles: Durations, Dynamics, and Forecasting, Princeton University Press.

Duarte, A. J. M., Issler, J. V. and Spacov, A. (2004). Indicadores Coincidentes de Atividade Econômica e uma Cronologia de Recessões para o Brasil, Pesquisa e Planejamento Econômico 34(1): 1-38.

Ellery Junior, R. G., Gomes, V. and Sachsida, A. (2002). Business cycle fluctuations in Brazil, Revista Brasileira de Economia 56(2): 269-308.

Estrella, A. and Mishkin, F. (1998). Predicting U.S. recessions: Financial variables as leading indicators, Review of Economics and Statistics 80(1): 45-61. 
Gallardo, M. and Pedersen, M. (2007). Un Sistema de Indicadores Líderes Compuestos para la Región de América Latina, Serie Estúdios Estadísticos y Prospectivos, CEPAL.

Granger, C. (1969). Investigating causal relations by econometric models and cross-spectral methods, Econometrica 37(3): 424-438.

Gyomai, G. and Guidetti., E. (2012). OECD System of Composite Leading Indicators, OECD.

URL: http://www. oecd.org/sdd/leading-indicators / $41629509 \cdot \mathrm{pdf}$

Hamilton, J. D. (2018). Why you should never use the Hodrick-Prescott filter, Review of Economics and Statistics 100(5): 831-843.

Harding, D. and Pagan, A. (2002). Dissecting the cycle: A methodological investigation, Journal of Monetary Economics 49: 365-81.

Hollauer, G. E., Issler, J. V. and Notini, H. H. (2009). Novo indicador coincidente para a atividade industrial brasileira, Revista de Economia Aplicada 13: 5-28.

Issler, J., Notini, H. and Rodrigues, C. (2009). Constructing coincident and leading indices of economic activity for the Brazilian economy, $F G V$ EPGE - Ensaios Econômicos 694.

URL: http://bibliotecadigital.fgv.br/dspace/ handle/10438/2680

Issler, J., Pimentel, L. and Rodrigues, C. (2019). Uma medida de PIB mensal para o Brasil usando o term spread, Revista Brasileira de Economia 73(1): 53-75.

Koopmans, T. C. (1947). Measurement without theory, Review of Economic Statistics 29: 161-72.

Lahiri, K. and Moore, G. H. E. (1992). Leading Economic Indicators: New Approaches and Forecasting Records, Cambridge University Press.

Lucas, Jr., R. E. (1977). Understanding business cycles, Carnegie-Rochester Conference Series on Public Policy 5: 7-29.

Marcellino, M. (2006). Leading indicators, Handbook of Economic Forecasting 1: 879-960. 
Moore, G. H. (1961). Statistical indicators of cyclical revivals and recessions, NBER Business Cycle Indicators 1: 184-260.

Moore, G. H. and Shiskin, J. (1967). Indicators of Business Expansions and Contractions, National Bureau of Economic Research.

Morais, I. A. C. (2013). Ciclo e indicadores antecedentes na indústria do Rio Grande do Sul, Nova Economia 20(1): 133-154.

Morais, I. A. C. and Frainer, V. (2005). Uma investigação sobre o ciclo dos negócios na indústria da Bahia, Revista Econômica do Nordeste 36: 378410.

Morais, I. A. C. and Portugal, M. S. (2008). Business cycle in the industrial production of Brazilian states, Revista Análise Econômica - UFRGS 50: 120.

NCER (2019). Business Cycle Dating Programs (BBQ), Technical report, National Center for Econometric Research.

URL: http: //www.ncer.edu.au/data/documents / BBQEXCELINSTRUCT . pdf

NYU (2015). Business-Cycle Indicators, The Global Economy, New York University's Center for Global Economy and Business.

Oliveira, F. N. d. (2016). Financial and real sector leading indicators of recessions in Brazil using probabilistic models, Revista Brasileira de Economia 70(3): 337-355.

Phillips, P. C. B. and Jin, S. (2015). Business Cycles, Trend Elimination, and the HP Filter, Discussion Paper 2005, Cowles Foundation.

URL: https: //papers.ssrn.com/sol3/papers.cfm? abstract_id=2622477

Picchetti, P. and Toledo, C. (2002). Estimating and interpreting a common stochastic component for the Brazilian industrial production index, Revista Brasileira de Economia 56: 107-120.

SEFAZRJ (2018). Contas de Governo Exercício- Demonstrações Contábeis e Notas Explicativas, Secretaria da Fazenda do Rio de Janeiro.

Stock, J. H. and Watson, M. W. (1989). New indexes of leading and coincident economic indicators, NBER Macroeconomic Annual 4: 351-409. 
Stock, J. H. and Watson, M. W. (1993). A Procedure for Predicting Recessions with Leading Economic Indicators: Econometric Issues and Recent Experience, Working Paper 4041, NBER.

Stock, J. and Watson, M. (1988a). A New Approach to Leading Economic Indicators, Harvard University, Kennedy School of Government.

Stock, J. and Watson, M. (1988b). A Probability Model of the Coincident Economic Indicators, Working Paper 2772, NBER.

TCB (2001). Business Cycle Indicators Handbook, The Conference Board.

URL: https: //www.conference-board.org/pdf_free/ economics/bci/BCI-Handbook.pdf

Zarnowitz, V. and Ozyildirim, A. (2006). Time series decomposition and measurement of business cycles, trends and growth cycles, Journal of Monetary Economics 53(7): 1717-1739.

Zhang, W. and Zhuang, J. (2002). Leading indicators of business cycles in Malaysia and the Philippines, Working Paper 32, ERD. 


\section{A. Additional tables and figures}

\section{Figure A1}

Cross-correlation results for crude oil export Brazil and crude oil production Rio de Janeiro

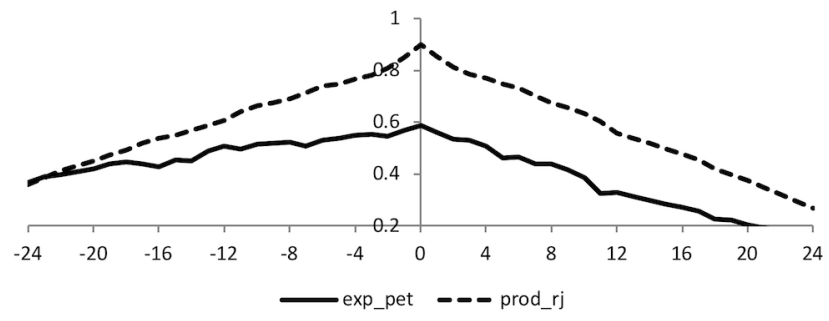

Figure A2

Cross-correlation results for electricity consumption in Brazilian southeastern region and Petrobras preferential stocks

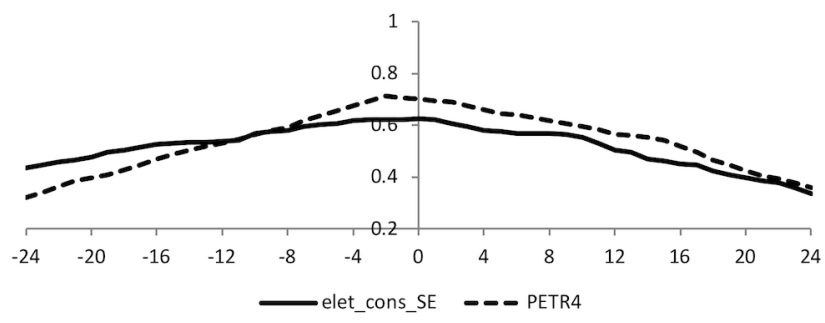

Figure A3

Cross-correlation results for foreign direct investment and SWAP DI x Pre 360 days

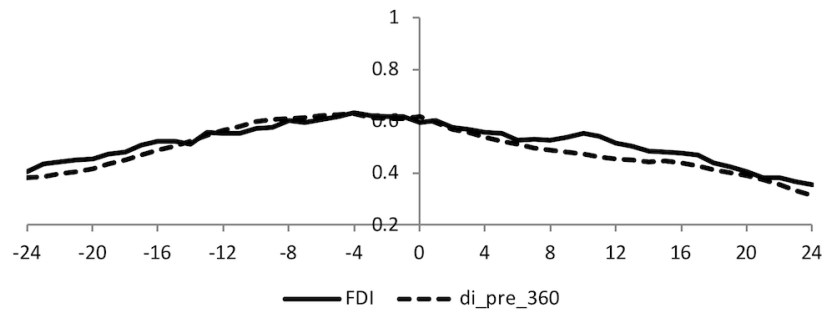


Table A1

Potential leading series database

\begin{tabular}{|c|c|c|c|c|}
\hline \# & series & source & seasonally adjusted & stationary \\
\hline 01 & Crude oil export Brazil & ANP & X-13 ARIMA SEATS & $1^{\text {st }}$ diff. \\
\hline 02 & Crude oil import Brazil & ANP & X-13 ARIMA SEATS & Level \\
\hline 03 & Crude oil production Brazil & ANP & X-13 ARIMA SEATS & $1^{\text {st }}$ diff. \\
\hline 04 & Crude oil production Rio de Janeiro & ANP & X-13 ARIMA SEATS & $1^{\text {st }}$ diff. \\
\hline 05 & Oil products import Brazil & ANP & X-13 ARIMA SEATS & $1^{\text {st }}$ diff. \\
\hline 06 & Oil processing in refinery & ANP & X-13 ARIMA SEATS & $1^{\text {st }}$ diff. \\
\hline 07 & Oil products sale Brazil & ANP & X-13 ARIMA SEATS & $1^{\text {st }}$ diff. \\
\hline 08 & Benchmark interest rate - SELIC overnight & $\mathrm{BCB}$ & - & $1^{\text {st }}$ diff. \\
\hline 09 & CDI overnight & $\mathrm{BCB}$ & - & $1^{\text {st }}$ diff. \\
\hline 10 & Brazilian broad money supply (MO) & BCB & X-13 ARIMA SEATS & $1^{\text {st }}$ diff. \\
\hline 11 & Brazilian broad money supply (M1) & $\mathrm{BCB}$ & X-13 ARIMA SEATS & $1^{\text {st }}$ diff. \\
\hline 12 & Brazilian broad money supply (M2) & $\mathrm{BCB}$ & X-13 ARIMA SEATS & $1^{\text {st }}$ diff. \\
\hline 13 & Foreign Direct Investment & $\mathrm{BCB}$ & X-13 ARIMA SEATS & $1^{\text {st }}$ diff. \\
\hline 14 & $\mathrm{IBC}-\mathrm{Br}$ & BCB & Source & $1^{\text {st }}$ diff. \\
\hline 15 & Foreign exchange rate $(\mathrm{R} \$ / \mathrm{U} \$)$ & $\mathrm{BCB}$ & - & $1^{\text {st }}$ diff. \\
\hline 16 & SWAP DIxPre 180 & $\mathrm{BCB}$ & - & $1^{\text {st }}$ diff. \\
\hline 17 & SWAP DIxPre 360 & $\mathrm{BCB}$ & - & $1^{\text {st }}$ diff. \\
\hline 18 & CDS Brazil -5 years & Bloomberg & - & Level \\
\hline 19 & CDS PETR $4-5$ years & Bloomberg & - & $1^{\text {st }}$ diff. \\
\hline 20 & Volatility index (VIX) & CBOE & - & Level \\
\hline 21 & Oil volatility index (OVX) & $\mathrm{CBOE}$ & - & Level \\
\hline 22 & Real industry's revenue - Brazil & $\mathrm{CNI}$ & Source & $1^{\text {st }}$ diff. \\
\hline 23 & Work hours in the industry - Brazil & $\mathrm{CNI}$ & Source & $1^{\text {st }}$ diff. \\
\hline 24 & Employment level in the industry - Brazil & $\mathrm{CNI}$ & Source & $1^{\text {st }}$ diff. \\
\hline 25 & Confidence index in the extractive industry & $\mathrm{CNI}$ & X-13 ARIMA SEATS & $1^{\text {st }}$ diff. \\
\hline 26 & Confidence index in the transformation industry & $\mathrm{CNI}$ & X-13 ARIMA SEATS & $1^{\text {st }}$ diff. \\
\hline 27 & CPB world trade monitor & $\mathrm{CPB}$ & X-13 ARIMA SEATS & $1^{\text {st }}$ diff. \\
\hline 28 & Electricity consumption in Brazilian southeastern region & Eletrobras & X-13 ARIMA SEATS & $1^{\text {st }}$ diff. \\
\hline 29 & Brent spot brice & EIA & X-13 ARIMA SEATS & $1^{\text {st }}$ diff. \\
\hline 30 & WTI spot price & EIA & X-13 ARIMA SEATS & $1^{\text {st }}$ diff. \\
\hline 31 & Nymex contract 4 & EIA & X-13 ARIMA SEATS & $1^{\text {st }}$ diff. \\
\hline 32 & Spread Nymex contract 4 and WTI spot & EIA & - & Level \\
\hline 33 & Global oil production & EIA & X-13 ARIMA SEATS & $1^{\text {st }}$ diff. \\
\hline 34 & OECD oil consumption & EIA & X-13 ARIMA SEATS & $1^{\text {st }}$ diff. \\
\hline 35 & OECD oil stocks & EIA & X-13 ARIMA SEATS & $1^{\text {st }}$ diff. \\
\hline 36 & Consumer confidence index & Fecomércio & X-13 ARIMA SEATS & $1^{\text {st }}$ diff. \\
\hline 37 & Consumer expectation index & Fecomércio & X-13 ARIMA SEATS & $1^{\text {st }}$ diff. \\
\hline 38 & Current economic condition index & Fecomércio & X-13 ARIMA SEATS & $1^{\text {st }}$ diff. \\
\hline 39 & Inflation - IGP & FGV & & Level \\
\hline 40 & Industry capacity utilization level & FGV & Source & $1^{\text {st }}$ diff. \\
\hline 41 & Real industry's revenue - Rio de Janeiro & Firjan & X-13 ARIMA SEATS & Level \\
\hline 42 & Industry utilization capacity index & Firjan & X-13 ARIMA SEATS & $1^{\text {st }}$ diff. \\
\hline 43 & Employment level in the industry - Rio de Janeiro & Firjan & X-13 ARIMA SEATS & $1^{\text {st }}$ diff. \\
\hline 44 & Industry salary level & Firjan & X-13 ARIMA SEATS & $1^{\text {st }}$ diff. \\
\hline 45 & Work hours in the industry - Rio de Janeiro & Firjan & X-13 ARIMA SEATS & $1^{\text {st }}$ diff. \\
\hline 46 & Export prices & FUNCEX & X-13 ARIMA SEATS & $1^{\text {st }}$ diff. \\
\hline 47 & PIM-PF Capital Goods & IBGE & Source & $1^{\text {st }}$ diff. \\
\hline 48 & PIM-PF Intermediate goods & IBGE & Source & $1^{\text {st }}$ diff. \\
\hline 49 & Inflation - IPCA & IBGE & - & Level \\
\hline 50 & CAGED Admissions & Government & X-13 ARIMA SEATS & $1^{\text {st }}$ diff. \\
\hline 51 & Capital goods import & Government & X-13 ARIMA SEATS & $1^{\text {st }}$ diff. \\
\hline 52 & Composite leading indicator - Brazil & OECD & - & Level \\
\hline 53 & Composite leading indicator - China & OECD & - & Level \\
\hline 54 & Composite leading indicator - G7 & OECD & - & Level \\
\hline 55 & Composite leading indicator - OECD & OECD & - & Level \\
\hline 56 & Business confidence index - Brazil & OECD & X-13 ARIMA SEATS & Level \\
\hline 57 & Business confidence index - G7 & OECD & X-13 ARIMA SEATS & Level \\
\hline 58 & Business confidence index - OECD & OECD & X-13 ARIMA SEATS & Level \\
\hline 59 & Ibovespa & Yahoo Finance & - & $1^{\text {st }}$ diff. \\
\hline 60 & New York Stock Exchange (NYSE) & Yahoo Finance & - & $1^{\text {st }}$ diff. \\
\hline 61 & Petrobras preferential stock (PETR4) & Yahoo Finance & - & $1^{\text {st }}$ diff. \\
\hline
\end{tabular}


Table A2

Quadratic probability score for the composite leading indicator components from lags -1 to -8

\begin{tabular}{lcccccccc}
\hline series & lag -1 & lag -2 & lag -3 & lag -4 & lag -5 & lag -6 & lag -7 & lag -8 \\
\hline prod_rj & 0.21 & 0.19 & 0.23 & 0.26 & 0.27 & 0.30 & 0.32 & 0.35 \\
exp_pet & 0.36 & 0.36 & 0.35 & 0.36 & 0.36 & 0.37 & 0.38 & 0.40 \\
cons_elet_se & 0.51 & 0.49 & 0.49 & 0.46 & 0.44 & 0.40 & 0.37 & 0.35 \\
PETR4 & 0.38 & 0.38 & 0.36 & 0.37 & 0.37 & 0.37 & 0.37 & 0.38 \\
FDI & 0.46 & 0.44 & 0.42 & 0.41 & 0.39 & 0.38 & 0.37 & 0.37 \\
di_pre_360 & 0.47 & 0.47 & 0.46 & 0.46 & 0.45 & 0.45 & 0.45 & 0.45 \\
\hline
\end{tabular}

Table A3

Quadratic probability score for the composite leading indicator components from lags -9 to -16

\begin{tabular}{lccccccccc}
\hline series & lag -9 & lag -10 & lag -11 & lag -12 & lag -13 & lag -14 & lag -15 & lag -16 \\
\hline prod_rj & 0.39 & 0.40 & 0.43 & 0.45 & 0.45 & 0.47 & 0.47 & 0.47 \\
exp_pet & 0.41 & 0.42 & 0.44 & 0.46 & 0.49 & 0.49 & 0.51 & 0.51 \\
cons_elet_se & 0.33 & 0.30 & 0.30 & 0.29 & 0.30 & 0.31 & 0.32 & 0.32 \\
PETR4 & 0.38 & 0.39 & 0.39 & 0.38 & 0.37 & 0.37 & 0.37 & 0.37 \\
FDI & 0.39 & 0.39 & 0.39 & 0.40 & 0.41 & 0.44 & 0.46 & 0.48 \\
di_pre_360 & 0.43 & 0.41 & 0.40 & 0.39 & 0.38 & 0.38 & 0.38 & 0.39 \\
\hline
\end{tabular}

Table A4

Granger causality results for the composite leading indicator components in level

\begin{tabular}{lccc}
\hline null hypothesis & $F$-statistic & Probability & AIC \\
\hline PROD_RJ does not Granger Cause REFERENCE & 2,06537 & 0,0868 & 4 \\
REFERENCE does not Granger Cause PROD_RJ & 1,31329 & 0,2392 & \\
EXP_PET does not Granger Cause REFERENCE & 2,24975 & 0,051 & \\
REFERENCE does not Granger Cause EXP_PET & 0,70247 & 0,648 & 6 \\
CONS_ELET_SE does not Granger Cause REFERENCE & 2,48385 & 0,086 & \multirow{2}{*}{2} \\
REFERENCE does not Granger Cause CONS_ELET_SE & 0,71487 & 0,4905 & \\
PETR4 does not Granger Cause REFERENCE & 1,52559 & 0,0965 & 3 \\
REFERENCE does not Granger Cause PETR4 & 0,86157 & 0,3544 & \\
FDI does not Granger Cause REFERENCE & 9,00582 & 0,0002 & 2 \\
REFERENCE does not Granger Cause FDI & 1,40765 & 0,2044 & \\
DI_PRE_360 does not Granger Cause REFERENCE & 3,46359 & 0,0642 & 5 \\
REFERENCE does not Granger Cause DI_PRE_360 & 1,51499 & 0,2198 & \\
\hline
\end{tabular}


Table A5

Granger causality results for the composite leading indicator components stationary

\begin{tabular}{lccc}
\hline null hypothesis & $F$-statistic & Probability & AIC \\
\hline PROD_RJ does not Granger Cause REFERENCE & 5,02483 & 0,0022 & \multirow{2}{*}{3} \\
REFERENCE does not Granger Cause PROD_RJ & 0,13818 & 0,9371 & \\
EXP_PET does not Granger Cause REFERENCE & 1,99982 & 0,0804 & 7 \\
REFERENCE does not Granger Cause EXP_PET & 1,39292 & 0,2194 & \\
CONS_ELET_SE does not Granger Cause REFERENCE & 2,75286 & 0,0986 & 1 \\
REFERENCE does not Granger Cause CONS_ELET_SE & 0,15718 & 0,6922 & \\
PETR4 does not Granger Cause REFERENCE & 2,01437 & 0,0171 & 2 \\
REFERENCE does not Granger Cause PETR4 & 1,35978 & 0,2247 & 2 \\
FDI does not Granger Cause REFERENCE & 4,42009 & 0,0367 & 2 \\
REFERENCE does not Granger Cause FDI & 0,05651 & 0,8123 & \\
DI_PRE_360 does not Granger Cause REFERENCE & 4,15609 & 0,0428 & 4 \\
REFERENCE does not Granger Cause DI_PRE_360 & 1,38686 & 0,2403 & \\
\hline
\end{tabular}

Table A6

Bivariate probit model results for the composite leading indicator components

\begin{tabular}{lccc}
\hline variable & optimum lag QPS & Z-Statistic & Probability \\
\hline prod_rj & 2 & -2.0685 & 0.0386 \\
exp_pet & 3 & 2.517864 & 0.0118 \\
cons_elet_SE & 12 & 1.915566 & 0.0554 \\
Petr4 & 3 & -1.98859 & 0.0467 \\
FDI & 7 & -1.94946 & 0.0512 \\
di_pre_360 & 13 & 2.705671 & 0.0068 \\
\hline
\end{tabular}

Table A7

Descriptive statistis of the series selected for the final composite leading indicator (CLI)

\begin{tabular}{lccccccc}
\hline variable & mean & p50 & sd & min & max & skewness & kurtosis \\
\hline petr4 & 16.314 & 16.358 & 8.12 & 3.275 & 40.512 & 0.403 & 2.648 \\
prod_rj & $4.80 \mathrm{E}+07$ & $4.80 \mathrm{E}+07$ & $6.20 \mathrm{E}+06$ & $3.40 \mathrm{E}+07$ & $6.40 \mathrm{E}+07$ & -0.051 & 2.478 \\
ied & 844.554 & 514.94 & 1198.227 & 14.37 & $1.30 \mathrm{E}+04$ & 5.588 & 52.545 \\
cons_elet & $1.80 \mathrm{E}+04$ & $1.90 \mathrm{E}+04$ & 2334.772 & $1.20 \mathrm{E}+04$ & $2.10 \mathrm{E}+04$ & -0.762 & 2.252 \\
di_pre_360 & -13.127 & -12.02 & 5.053 & -31.18 & -6.35 & -1.287 & 4.882 \\
exp_pet & $1.70 \mathrm{E}+07$ & $1.50 \mathrm{E}+07$ & $9.60 \mathrm{E}+06$ & $1.10 \mathrm{E}+06$ & $5.60 \mathrm{E}+07$ & 1.083 & 4.382 \\
\hline
\end{tabular}

Note: number of observations for all variables equals 209 (year-month). 